\title{
Tall trends: quantifying the skyscraper phenomenon
}

\author{
Jason Gabel ${ }^{1 *}$ \\ ${ }^{1}$ Council on Tall Buildings and Urban Habitat, 104 South Michigan Ave., Suite 620, Chicago, IL, \\ 60603, United States
}

\begin{abstract}
The world continues to witness an explosion of growth in the number of 200-plus-meter skyscrapers, with three straight years of recordbreaking completions (from 2014 to 2016) and a 441 percent increase on the total number of such towers in the 21 st century, from 265 in 2000 to 1,168 at the end of 2016. Fueled largely by strong economic performance, much of this activity is centered in Asia and the Middle East, upending longstanding geopolitical trends. China in particular has dominated worldwide skyscraper construction, accounting for two-thirds of all completions in the last calendar year (2016). Further, the traditional role of the skyscraper has diversified, with residential and mixed-use buildings accounting for a greater share of 200-plus-meter buildings. This paper explores these interconnected trends in detail and analyzes both the causes and impacts of an evolving skyscraper industry.
\end{abstract}

\section{Overview - Trends in 2016 and 2017}

The Council on Tall Buildings and Urban Habitat (CTBUH) releases an annual study of yearly 200-plus-meter skyscraper completions, investigating year-over-year changes in skyscraper locations, functions, and construction material. These reports create a snapshot of an evolving skyscraper industry, one that has seen exponential growth in recent years, driven primarily by a massive shift in skyscraper construction from the United States to Asia and the Middle East, particularly China [1].

Most recently, CTBUH determined that 128 buildings of 200 meters' height or greater were completed around the world in 2016 - setting a new record for annual tall building completions and marking the third consecutive record-breaking year (see Fig. 1). Of those 128 buildings, a total of 10 supertalls (buildings of 300 meters or higher) were completed in 2016, the third-largest number of supertall completions of any year [2].

The tallest building to complete in 2016 was Guangzhou CTF Finance Centre, which stood at the time as the tallest building in Guangzhou, the second-tallest building in China, and the fifth-tallest building in the world at 530 meters. However, the first few months of 2017 witnessed the completion of two even taller skyscrapers; namely Ping An Finance Center (599 meters) and Lotte World Tower (555 meters), which are currently the fourthand fifth-tallest towers worldwide. The 2015 CTBUH report had originally predicted that

*Corresponding author: jgabel@ctbuh.org 
these supertalls would complete in 2016, illustrating the difficulty of anticipating skyscraper completions and, of course, the technical and logistical challenges inherent in completing these behemoth structures [3].

Many of the major trends in 2016 remain consistent through the first part of 2017, confirming long-term tendencies that have shaped the industry over the last few decades. Although it is very difficult to predict completion dates of buildings at this scale, the CTBUH predicts that 2017 will see the completion of anywhere between 126 and 150 buildings of 200 meters or greater and 12 to 20 supertalls, meaning that the records set in 2016 are likely to be broken for a fourth straight year.

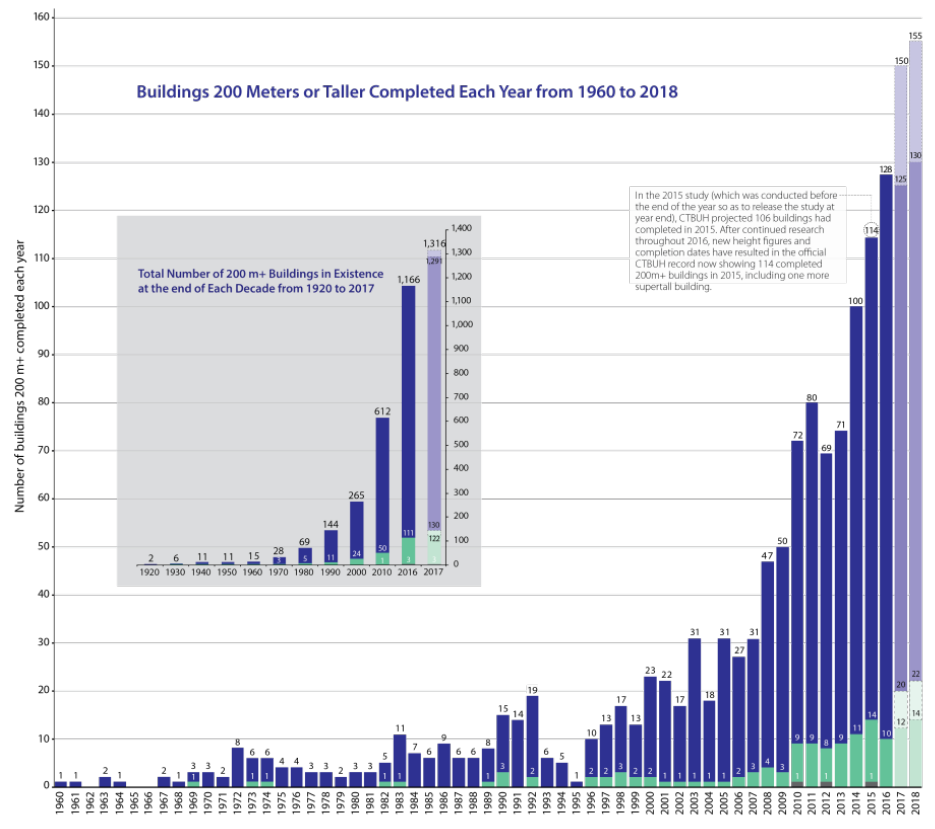

Fig. 1. Buildings 200 meters or taller completed each year from 1960 to 2018.

\section{Key Worldwide Market Snapshots}

Although Asia continues to dominate the skyscraper industry, other regional markets are experiencing growth in the typology, some for the first time. The Middle East continues to draw attention to itself with some of the tallest buildings completed, while Europe, Oceania, and South America are just now waking up to the benefits of building tall. Meanwhile, North America, once the unrivaled leader in skyscraper construction, is slowly reversing a long-term decline in overall completions.

\subsection{Asia (Excluding Middle East)}

The momentum of Asia has been unyielding for many years, and 2016 only served to further reinforce this trend. The region recorded 107 of the 128 completions for that year, or 84 percent of the total (see Fig. 2). A majority of those buildings are located in China, which completed the most 200-meter-plus buildings (84) of any country in the world for the ninth straight year (see Fig. 2). Thirty-one cities in China had at least one 200-meter-plus building completion, with Shenzhen outperforming any other city in the world, with 11 (to 
put that in perspective, that is more than any other country completed in 2016. The US completed seven 200-plus-meter buildings, and was second only to China).

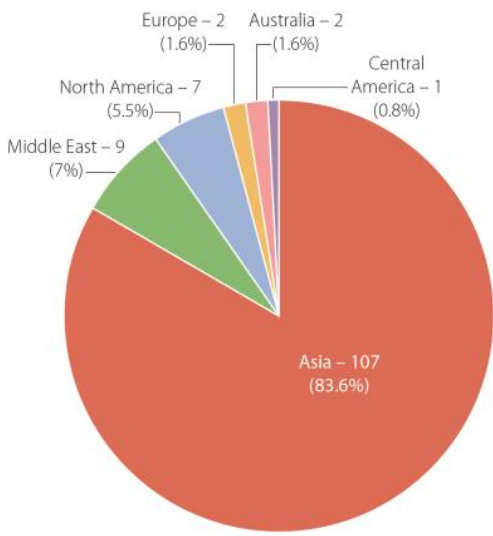

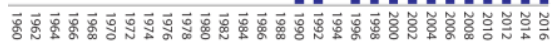

Fig. 2. (Left) Buildings 200 meters or taller completed in 2016 by Region and (Right) Annual 200meter-plus building completions in China since 1960.

To date, 2017 has seen the continuation of Asia's and China's dominance. Although Asia accounts for just over half of all confirmed completions through May 2017, the continent accounts for 163 out of the 230 buildings that CTBUH has flagged for possible completion in the calendar year. Of those 163 potential buildings in Asia, 115 are located in China. Of course, it is highly unlikely that all of those buildings will complete before the end of the year, but ongoing construction is generally a good indicator of future trends.

Beyond China - South Korea, Indonesia, and The Philippines led the way in Asia with six, five, and four completions, respectively, in 2016 (see Fig. 3).

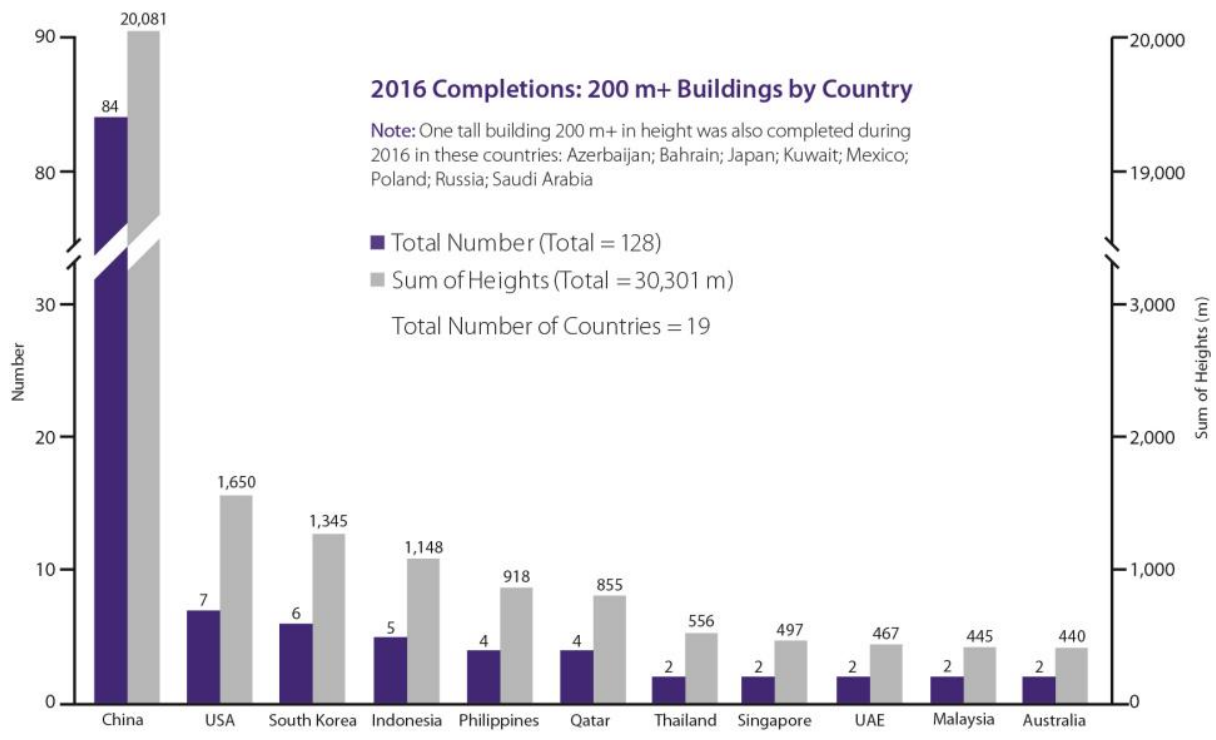

Fig. 3. 2016 completions by country. 
South Korea's six completions doubles its count of three from 2015, but all six can be attributed to a single development, the Ilsan Yojin Y-City Complex in Goyang, suggesting that the country's overall completion numbers are highly dependent on a handful of major skyscraper complexes. For example, only one 200-plus-meter building was completed in 2014, but nine were completed in 2013, with all but one of those linked to a single development.

So far, Lotte Tower is the only 200-plus-meter building that has completed in South Korea in 2017; however, it is a major accomplishment as the fifth-tallest building worldwide. A further seven buildings are targeted for potential 2017 completions, meaning that South Korea will likely find itself near the top of the country list at the end of the year. Indonesia and The Philippines are similarly poised to retain their status as secondary drivers to Asia's high-rise boom behind China, with eight and six expected 2017 completions, respectively.

\subsection{Australia}

The land down under boasted two completions in 2016, Vision Apartments in Melbourne at 223 meters and International Towers - Tower 1 in Sydney at 217 meters. The annual trickle of tall buildings coming online in the country is expected to continue in the years ahead, with eleven 200-meter-plus buildings currently under construction or topped out, with completion years ranging from 2017 to 2020 [2]. So far in 2017, the country has already recorded one such completion with news that the 203-meter EQ Tower in Melbourne finished.

\subsection{Central and South America}

The Central America region had only one 200-meter-plus completion in 2016, in the form of Mexico City's Torre Reforma. The 246-meter tower was recognized as a CTBUH 2016 Awards finalist for the Americas region for its innovative structural configuration, significant opacity along one of its façades, and the preservation of a historic building at its base [4]. The tower is now the tallest building in Mexico. Two towers of similar height could complete in Mexico in 2017, Torre Paradox in Mexico City and Torre KOI in San Pedro Garza García. At 279 meters, the latter is poised to become the tallest building in the country. Although South America saw no 200-plus-meter completions in 2016, 2017 could reverse that trend, with a number of currently rising towers that could finish within the year [2]. Colombia leads the way with three under-construction skyscrapers, Hotel Estelar Bocagrande in Cartagena and BD Bacata Torre 1 and 2 in Bogota. BD Bacata Torre 1 (260 meters) will be the tallest building in the country once complete. It is notable for its unique crowd-sourced development strategy. Meanwhile, Venezuela, Argentina, and Brazil are also expected to contribute to South America's resurgence in 2017.

\subsection{Europe}

Despite having a significant influx of tall building completions in 2015, 2016 saw the lowest number of 200-meter-plus completions in Europe (two) since 2009, in which it had zero (see Fig. 4). Notably, the year saw the completion of the 374-meter Vostok Tower, Moscow, the tallest component of the Federation Towers complex. After having begun construction in 2005, the tower had been 11 years in the making. It is now the tallest building in Europe, a title that previously belonged to OKO Residential Tower, a development that completed in 2015 just blocks away from Vostok Tower in the Moscow City district. 
Although there are no 200-plus-meter skyscrapers expected to complete in Russia in 2017, several buildings are in the pipeline for the remainder of the decade, including the country's future tallest, Lakhta Center in St. Petersburg. At 462 meters, it will be almost 100 meters taller than Vostok Tower. Also on the rise is Akhmat Tower in Grozny, which will also top the 400 -meter mark.

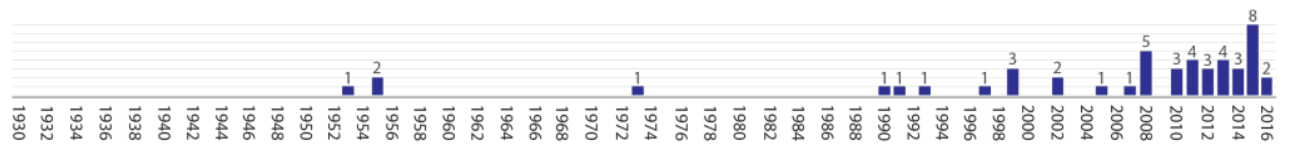

Fig. 4. Annual 200-meter-plus building completions in Europe since 1930.

The other 2016 European completion was Warsaw Spire, a 220-meter tower that represents the tallest of several new projects recently rising in the Polish capital. In terms of its height on the Warsaw skyline, the tower ranks second only to the Soviet-era Palace of Culture and Science, built in 1955. The majority of potential 2017 completions are found in Turkey, where six 200-plus-meter buildings are topped out or nearing that point, most notable the Skyland Istanbul complex, which will deliver two 284-meter towers. Additionally, Italy buoys the list with Turin's Regione Piemonte Headquarters, a 209-meter government high-rise.

\subsection{Middle East and Africa}

For the second year running, the Middle East ended 2016 with nine 200-meter-plus completions (see Fig. 5). This continues a steady trend of completions in the region, but pales in comparison to its all-time high of 23 in 2013, a spike that was attributed to a global post-recession recovery in tall building construction [5]. This is the first year since 2006 that the Middle East has not seen the completion of a supertall (300-plus-meter) building, but one should be wary of assuming that this is indicative of a regional swing away from the supertall height threshold. Projections show as many as five supertall buildings completing in the Middle East in 2017 [2].

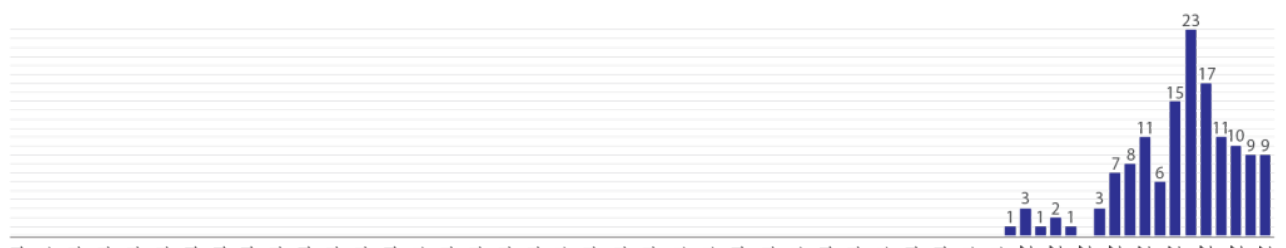

Fig. 5. Annual 200-meter-plus building completions in the Middle East since 1930.

In an unusual turn for the region, the United Arab Emirates did not have the greatest number of completions in the region for 2016. That accomplishment belonged to Qatar, which saw four towers completed in the calendar year. The UAE followed with just two completions, and Saudi Arabia, Kuwait, and Bahrain tied with one completion each. The tallest building to complete in the Middle East in 2016 was Regent Emirates Pearl, a 255meter tower in Abu Dhabi that twists along its height at a rate of approximately 0.481 degrees per floor.

Africa is expected to get points on the board in 2017 with the completion of Britam Tower in Nairobi. Notably, the topped-out tower is just the second 200-plus-meter building ever built on the continent, following only the Carlton Centre in Johannesburg, which remains Africa's tallest building at 223 meters. 


\subsection{North America}

Bouncing back from just four completions in 2015, North America saw the finalization of seven 200-meter-plus buildings in 2016, the greatest number since 2010, in which it also had seven (see Fig. 6). All of these buildings are located within the United States, and four are in New York City alone. Most of the buildings completed in the US were residential in function, with six of the seven incorporating living components, and just one incorporating office uses (10 Hudson Yards, 268 meters).

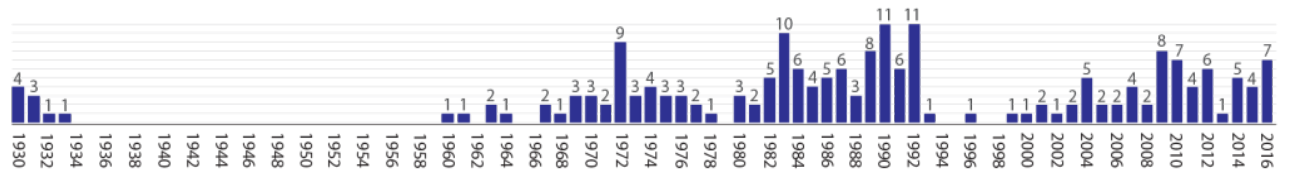

Fig. 6. Annual 200-meter-plus building completions in North America since 1930.

The tallest building to complete in the US was 30 Park Place, a 282-meter residential / hotel tower in Downtown Manhattan, accommodating a Four Season Hotel in the lower portion and luxury apartments above the 40th floor. Notably, the year also saw the opening of 56 Leonard Street, a tower that has been tracked closely throughout its development by the media given its unique «Jenga-like» design that extrudes upper-level penthouses on cantilevering floor slabs. 2017 seems likely to eclipse the success of the previous year with 14 potential completions in the United States in cities across the country, including New York, Chicago, Philadelphia, Miami, Seattle, San Francisco, Houston, and Los Angeles. An additional five buildings could complete in Canada as well.

\section{Completions by Function}

Interestingly, the functional split for tall building completions in 2016 remained almost perfectly consistent with that of previous years (see Fig. 7). Office functions have by far the highest share, representing 52 percent of completions with 67, achieving a consecutive alltime record over 2015, in which there were 53. Meanwhile, 37 mixed-use buildings were completed, representing 29 percent of the total; while 20 residential buildings came online with a share of 16 percent. Only three all-hotel towers were completed in 2016, representing just three percent of the total. Given that hotel functions are critical components of many mixed-use developments, the low number of completions for hotelonly towers does not indicate a downward trend for the function altogether. While that completion split is expected to remain relatively consistent in 2017, the share of all office buildings could fall as residential and mixed-use buildings become more popular. In particular, the share of residential buildings completing in 2017 could rise as high as 26 percent.

\section{Completions by Structural Material}

The number of buildings completed in 2016 with composite structural systems hit an alltime high, with 68, or 53 percent of the total (see Fig. 7). Composite construction represents an effort to use the optimal properties of steel and concrete and counteract their respective weaknesses. Thus, this material trend is expected to continue to dominate, particularly as tall buildings continue to proliferate in seismically active regions like China, which mandate robust structural responses [6]. 
Concrete construction took the remaining share of completions with 58, or 45 percent of the total. The significant use of concrete can be attributed to a combination of concrete's relative ubiquity and lower cost in many regions, as well as its comparative simplicity in construction, which would increase its appeal in regions with lower-skilled labor pools. In 2016, not a single building of 200 meters or higher was completed with an all-steel structural system. The use of steel in tall buildings has almost completely transitioned into composite construction. As of this writing, there are only twenty 200-meter-plus buildings currently under construction that employ all-steel structural systems, with the tallest being Akhmat Tower [2].
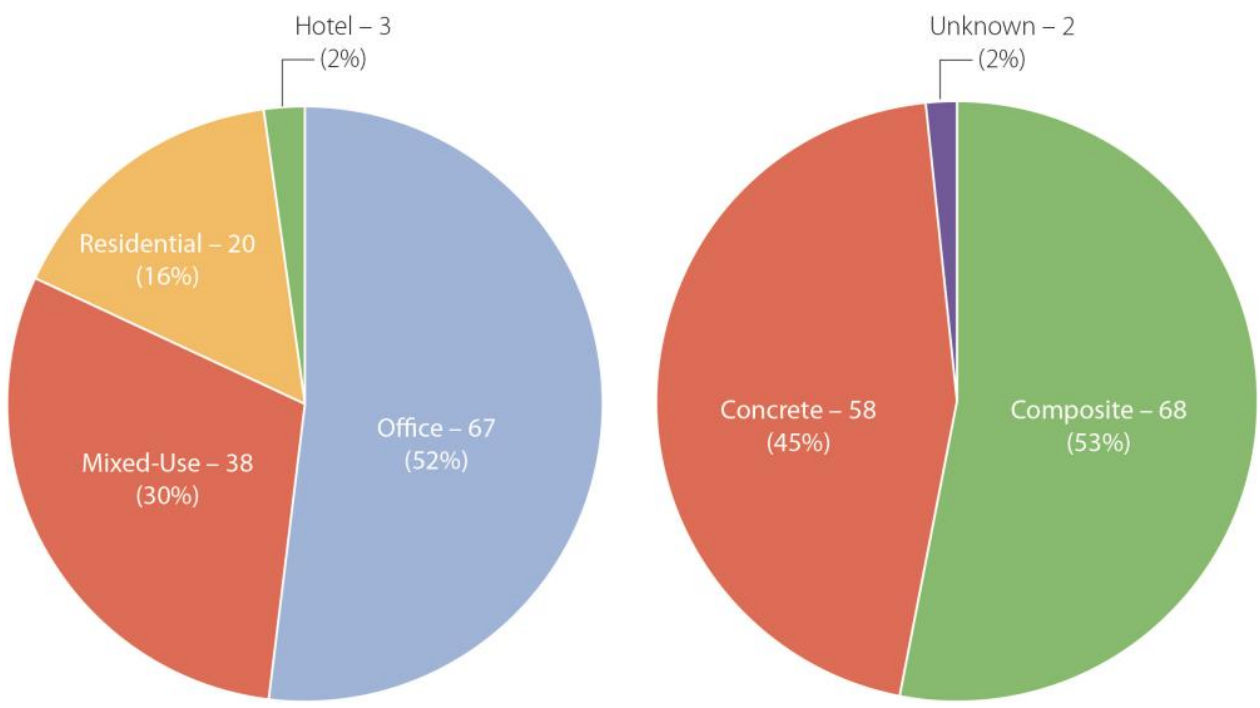

Fig. 7. (Left) Buildings 200 meters or taller completed in 2016 by Function and (Right) Buildings 200 meters or taller completed in 2016 by Structural Material.

\section{The World's 100 Tallest Buildings: 2016-2017 Impact}

In 2016, 10 buildings entered the list of the World's 100 Tallest Buildings (see Fig. 8). 2016 also marked the first year that every building on the 100 Tallest list was a supertall (300-plus meters tall). It follows that all 10 buildings entering the list also lie above this threshold, increasing the average height of the 100 tallest buildings from 357 meters in 2015 to 362 meters in 2016.

Through the first part of 2017, four more buildings have entered the list, including the fourth and fifth tallest (Ping An Finance Center and Lotte World Tower). The shortest building on the list is now Diwang International Fortune Center, Liuzhou, at 303 meters.

Mixed-use functions continue to enjoy a plurality in the 100 Tallest list, with 44 buildings. Meanwhile, office functions account for 37 buildings, down slightly from 40 at the end of 2016 (see Fig. 9). Residential and hotel functions have smaller shares, with 12 and seven buildings respectively.

The 100 Tallest list continues to be dominated by composite construction, with 52 buildings now employing composite systems (52 in 2016), up from 46 in 2015 (see Fig. 10). All-concrete and steel primary structures have experienced slight losses, down to 35 buildings for concrete and nine for steel. 


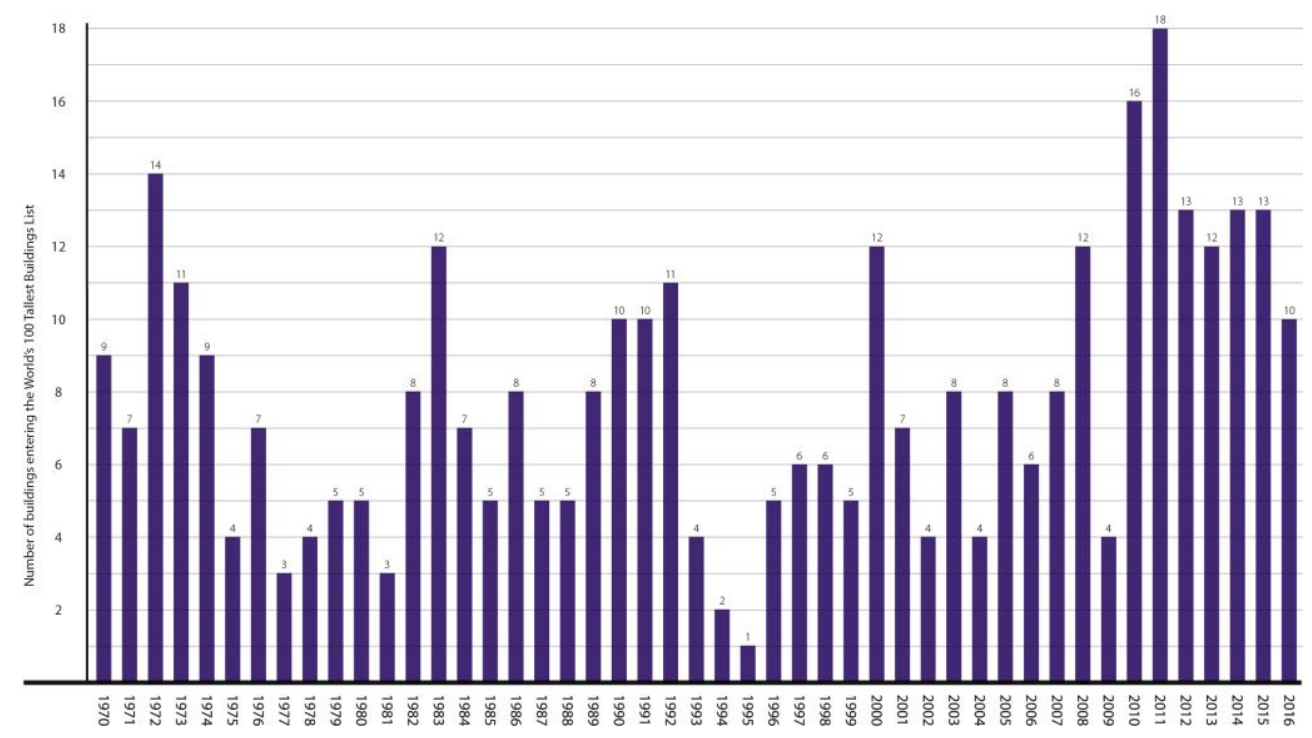

Fig. 8. Number of buildings entering the world's 100 tallest by Year.
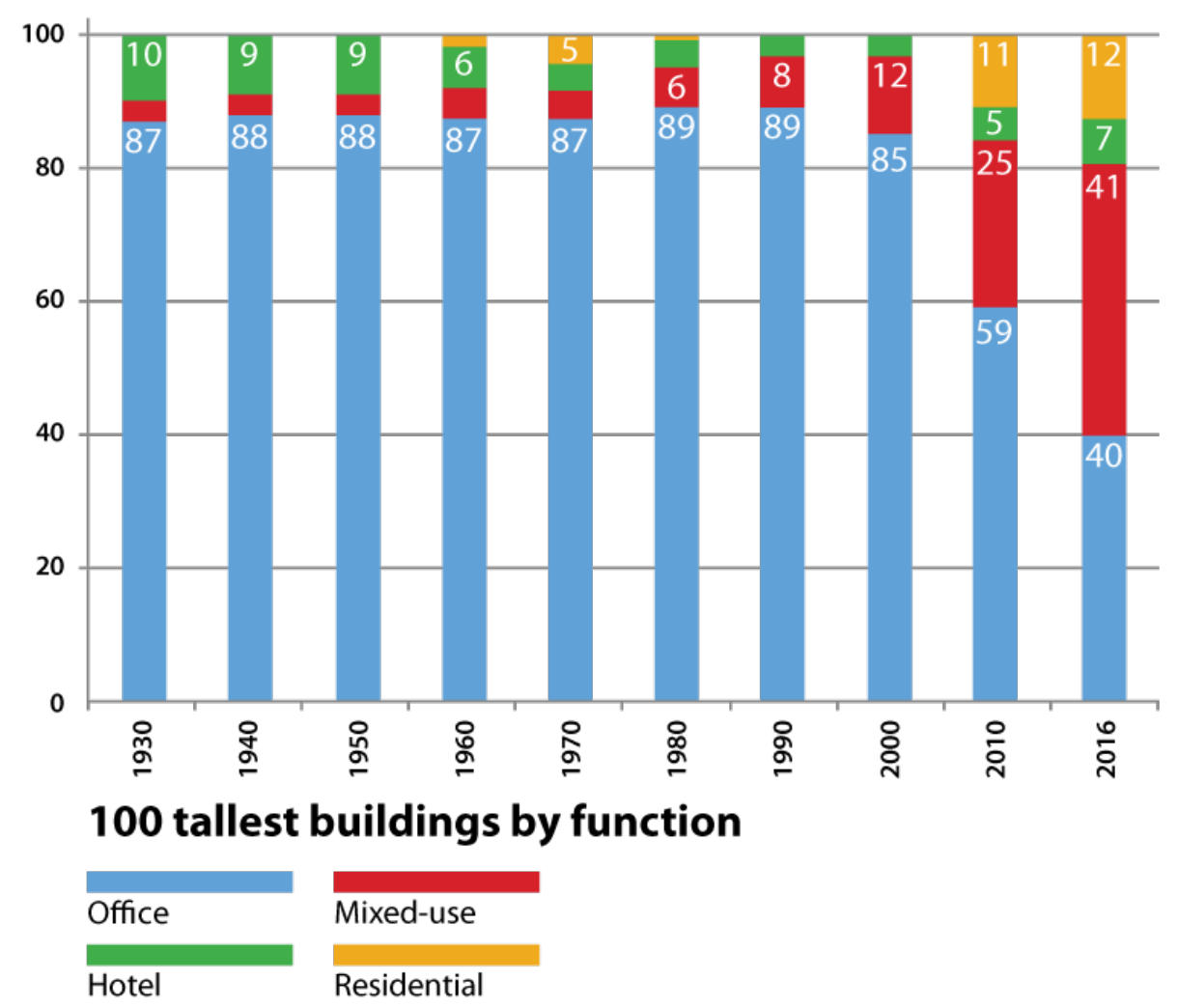

(c) Council on Tall Buildings and Urban Habitat

Fig. 9. The world's 100 tallest buildings over time by Function. 


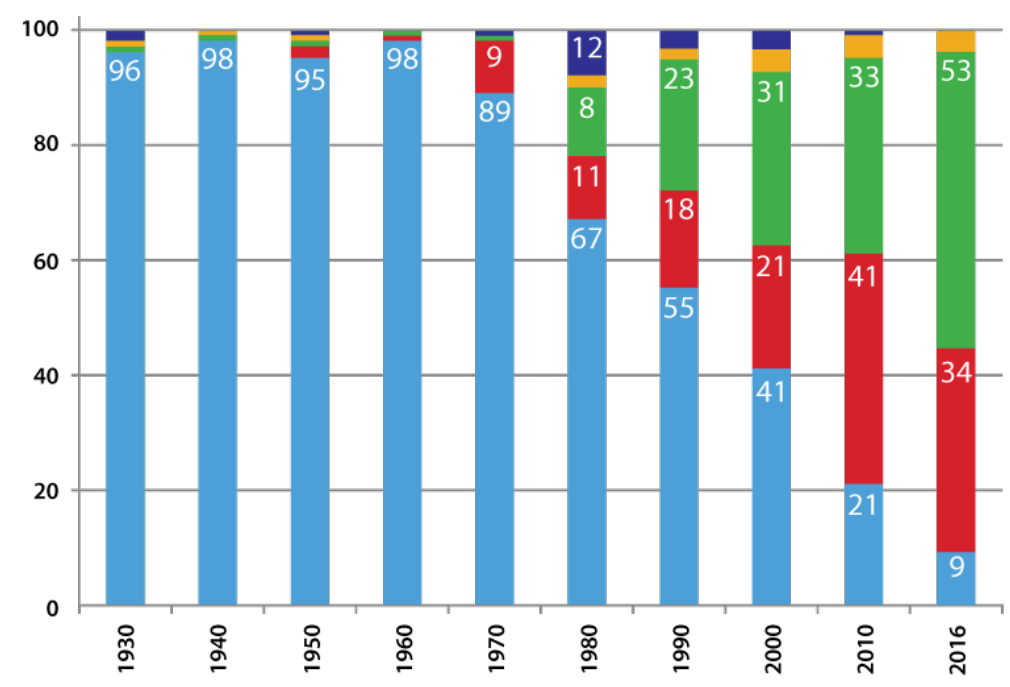

100 tallest buildings by material

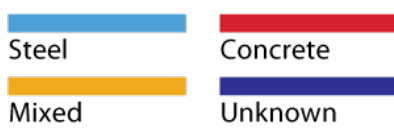

Composite

(c) Council on Tall Buildings and Urban Habitat

Fig. 10. The world's 100 tallest buildings over time by Material.

\section{Analysis}

For the third year running, the world has built more 200-meter-plus buildings in 2016 than any other year (128), beating the previous record of 114 in 2015. In 2015, we predicted that between 110 and 135 buildings would complete within this range in 2016, so it comes as no surprise that it was yet another record-breaking year in the skyscraper industry.

It's impossible to decouple the enormous boom in global skyscraper construction from the rapid urban development of China. Additionally, over the past several years, there has been a major uptick in the amount of real estate investment coming out of China, rather than remaining within it. This, in combination with a still-cooling national economy has caused some to assume that the era of unprecedented construction is on a downward decline. While that may be the case in the long run, short-term prospects remain high, with 328 buildings in the 200-plus-meter range currently under construction in the country.

It's safe to say that the role of the tall building in China will never truly fade, the only question that remains is how long it will continue to keep a majority share of tall building completions annually. With the closest contender in 2016 having only seven completions and China having 84 , it is clear that the gap will take a number of years to close. Perhaps the most indicative trend from this report highlighting China's status is the fact that the city of Shenzhen completed 11 buildings that were 200 meters or higher. This is more than any country other than China managed to complete, and represents a record number of 200 meter-plus buildings completed by a single city in any calendar year. With nine of these buildings accommodating pure office functions, and the remaining two combining office and either hotel or residential, the priorities for Shenzhen are clear: These buildings are strategic endeavors to stimulate the local and national economy with commerce, some of it 
originating internationally as a result of Shenzhen's status as a Special Economic Zone. The ethos is still very much in the realm of «if you build it, they will come»; we'll just have to wait and see if the wager is fruitful.

«Tallest» titles also reigned supreme in 2016, with 17 buildings completing that became the tallest in a city, country, or region. Just to name some of the most significant superlatives: Vostok Tower (374 meters) completed to become the tallest building in Europe, Russia, and Moscow; MahaNakhon (314 meters) completed as the tallest building in Thailand and Bangkok; Guangzhou CTF Finance Centre (530 meters) completed as the tallest building in Guangzhou, the second-tallest (now third) in China, and the fifth-tallest (now seventh) in the world; Torre Reforma (246 meters) became the tallest in Mexico and Mexico City; Tajong Pagar Centre (290 meters) is now the tallest in Singapore; Gama Tower became the tallest in Indonesia and Jakarta...the list continues.

2017 has already continued this trend with the completion of Lotte World Tower (555 meters) as the tallest in Seoul and Ping an Finance Center (599 meters) as the tallest in Shenzhen and second tallest in China. In each instance, the drivers behind these buildings remain constant: the desire to establish identity (whether for a commercial business or an entire locale), to enhance the skyline, to respond to urban population growth, and to maximize functional utility upon minimal land area.

\section{References}

1. J. Gabel, et al: CTBUH Year in Review: Tall Trends of 2016, CTBUH Journal 2017 Issue I, 38-47 (2017)

2. http://www.skyscrapercenter.com/, last accessed 2017/01/10

3. J. Gabel, et al: CTBUH Year in Review: Tall Trends of 2015, CTBUH Journal 2016 Issue I, 40-49 (2017)

4. A. Wood, H. Steven, Best Tall Buildings: A Global Overview of 2016 Skyscrapers, Council on Tall Buildings and Urban Habitat (2016)

5. D. Safarik, et al: CTBUH Year in Review: Tall Trends of 2014, CTBUH Journal 2014 Issue I, 38-47 (2017)

6. S. Zhang, et al: Tall Building Seismic Design Case Study per China and U.S. Codes. In: Safarik, D, CTBUH 2014 Shanghai Conference Proceedings, 617-624 Council on Tall Buildings and Urban Habitat (2014) 